\title{
Optical and electrical characterization of AIGaN based Schottky photodiodes after annealing at different temperatures
}

PNM Ngoepe*, WE Meyer, M Diale, FD Auret, L van Schalkwyk

Department of Physics, University of Pretoria, Private bag X20, Hatfield, 0028

\begin{abstract}
In this study a comparison is made between the optical and electrical properties of $\mathrm{Ni} / \mathrm{Au}$ and $\mathrm{Ni} / \mathrm{Ir} / \mathrm{Au}$ Schottky photodiodes based on $\mathrm{Al}_{0.35} \mathrm{Ga}_{0.65} \mathrm{~N}$. The effects of inserting Ir between $\mathrm{Ni}$ and $\mathrm{Au}$ are of particular interest. The comparison in the properties is done after annealing the photodiodes at different temperatures in an argon gas ambient. The reverse current decreased with annealing temperature up to $400{ }^{\circ} \mathrm{C}$ for the Ni/Au Schottky photodiode and up to $500{ }^{\circ} \mathrm{C}$ for the Ni/Ir/Au photodiode. The Schottky barrier heights increased with increasing annealing temperature. The responsivity of the $\mathrm{Ni} / \mathrm{Au}$ photodiode was higher than that of the $\mathrm{Ni} / \mathrm{Ir} / \mathrm{Au}$ photodiode. The transmission of the Ni/Au metal layer improved with increasing annealing temperature up to $500{ }^{\circ} \mathrm{C}$ and the best transmission of the $\mathrm{Ni} / \mathrm{Ir} / \mathrm{Au}$ metal layer was after 400 ${ }^{\circ} \mathrm{C}$ annealing.
\end{abstract}

Keywords: Annealing, Schottky photodiode, AlGaN

PACS: 73.40.Ei, 73.61.Ey, 78.66.Fd

\footnotetext{
"Corresponding author: Tel.: +27 12420 3508; fax: +12 3625288

e-mail address:phuti.ngoepe@up.ac.za
} 


\section{Introduction}

Aluminium Gallium Nitride $\left(\mathrm{Al}_{\mathrm{x}} \mathrm{Ga}_{1-\mathrm{x}} \mathrm{N}\right)$ is a ternary semiconductor with a tuneable bandgap, which implies that Schottky diodes manufactured on it are spectrally selective. By varying the Al to $\mathrm{Ga}$ ratio, and therefore the bandgap of the semiconductor, a specific cut-off wavelength can be selected. This property makes it possible to use AlGaN in a variety of devices such as UV detectors [1,2]. AlGaN based UV detectors have military, space, commercial, and biological applications $[3,4]$. Other properties that make it a good candidate for these applications include its good chemical and high thermal stability and the fact that it is a direct bandgap semiconductor. The $\mathrm{AlGaN}$ used for this particular study had a $35 \% \mathrm{Al}$ content. Multilayer metal systems have been investigated on $\mathrm{AlGaN} / \mathrm{GaN}$ based semiconductors [5-7]. In particular these studies have been done on Ni/Au metal schemes by inserting different metals between the $\mathrm{Ni}$ and $\mathrm{Au}$ in order to lower the reverse leakage current [8]. Annealing studies have also been performed with the aim of improving the electrical characteristics of various $\mathrm{AlGaN} / \mathrm{GaN}$ based devices $[8,9]$. These improvements have included lowering the reverse bias characteristics of the diodes and enhancing the barrier height. In this study we report on the effects of depositing Ir as a diffusion barrier between the $\mathrm{Ni}$ and $\mathrm{Au}$ in a Ni/Au Schottky contact on AlGaN. The evolution of the optical and electrical characteristics is also evaluated with increasing annealing temperature.

\section{Experimental}

The sample preparation included firstly degreasing the samples in trichloroethylene and isopropanol for 3 minutes in each solution. Secondly they were etched in boiling aqua regia for 10 minutes and then dipped in a $20 \% \mathrm{HCl}$ solution for 1 minute. After each of the dips the samples were rinsed in deionised water $[10,11]$. Lastly the samples were blow dried with nitrogen. Ni (20 ̊)/ Au (50 ̊) and Ni (20 ̊)/ Ir (30 ̊)/ Au (50 A) Schottky contacts were deposited on the $\mathrm{AlGaN}$ wafers in a resistive evaporation chamber and electron beam system respectively. These Schottky diodes had a diameter of $0.6 \mathrm{~mm}$. The Ti (150 ̊)/ Al (2200 $)$ / $\mathrm{Ni}(400 \AA) / \mathrm{Au}(500 \AA)$ ohmic contacts were deposited with the electron beam system. The Schottky metal schemes were also deposited onto a $6 \times 6 \mathrm{~mm}$ quartz substrate for transmission measurements. The Schottky photodiodes were isochronously annealed in an argon gas ambient at $200,300,400$, and $500{ }^{\circ} \mathrm{C}$ for 5 minutes in a Lindberg annealing 
furnace. The argon had a flow rate of 2 LPM. After every annealing temperature step the samples were electrically and optically characterised. The electrical characterisation consisted of current-voltage measurements in a dark environment. These measurements were done using an HP4140B pA Meter/DC Voltage Source. The optical characteristics consisted of measuring the transmission of radiation through $\mathrm{Ni} / \mathrm{Au}$ and $\mathrm{Ni} / \mathrm{Ir} / \mathrm{Au}$ metal layers which were deposited on the quartz substrate. The transmitted light was normalised with respect to the quartz substrate. These samples were annealed under the same conditions as the photodiodes. The transmission measurements were performed with a Perkin Elmer Lambda 25 UV/VIS Spectrometer. Photocurrent measurements were done under illumination from a Digikrom DK 240 1/4 meter monochromator with a $30 \mathrm{~W}$ deuterium lamp. The light source was calibrated using an optometer with a calibrated Si photodiode from 200 to $400 \mathrm{~nm}$.

\section{Results and discussion}

The I-V characteristics of the Ni/Au and Ni/Ir Au Schottky photodiode at lower temperatures have similar patterns as shown in Fig. 1 and Fig. 2. In the lower voltage region up to $0.8 \mathrm{~V}$ the principal current transport mechanism for the $\mathrm{Ni} / \mathrm{Au}$ diode measured after annealing at the temperatures 200, 300, and $400{ }^{\circ} \mathrm{C}$ was thermionic emission. The as deposited diode seemed to have some recombination current up to $0.2 \mathrm{~V}$. After $500{ }^{\circ} \mathrm{C}$ annealing, the forward bias characteristics of the Ni/Au Schottky diode began to deteriorate and showed a deviation from the ideal diode equation. The dominant current transport mechanism for the forward bias characteristics of the $\mathrm{Ni} / \mathrm{Ir} / \mathrm{Au}$ diode up to $0.8 \mathrm{~V}$ was thermionic emission. These mechanisms are consistent with thermionic emission theory [12]. The effect of series resistance was observed for voltages beyond the above mentioned regions. For lower annealing temperatures, the reverse currents of both photodiodes at $-1 \mathrm{~V}$ decreased with increasing annealing temperature. At $500{ }^{\circ} \mathrm{C}$ though the reverse current of the $\mathrm{Ni} / \mathrm{Au}$ Schottky diode began to increase. In contrast to this, the Ni/Ir/Au Schottky diode showed a continued decrease in reverse current, even after annealing at $500{ }^{\circ} \mathrm{C}$. The robustness of the device could be attributed to the Ir layer which prevented diffusion of Au through the Ni layer. Ir has a higher thermal stability than $\mathrm{Ni}$ and $\mathrm{Au}$ and has a greater density than both $\mathrm{Ni}$ and $\mathrm{Au}$. The diffusion of $\mathrm{Au}$ through $\mathrm{Ni}$ into the semiconductor has been known to cause deterioration of devices [8]. This degradation has also been attributed to the formation of metal gallides and/or nitrides [13]. An abnormality was observed for low reverse currents. As the reverse bias voltage increased, the currents of the $\mathrm{Ni} / \mathrm{Ir} / \mathrm{Au}$ Schottky diode decreased before 
increasing. This was observed in the 0 to $-0.2 \mathrm{~V}$ region of the I-V characteristics. This phenomenon was also seen after higher temperature annealing of the Ni/Au Schottky diode. This is probably due to deep traps in the depletion region emptying. The Schottky barrier heights of both Schottky diodes increased with increasing annealing temperature. The barrier height of the Ni/Au diode increased from 0.91 to $1.26 \mathrm{eV}$ and that of the $\mathrm{Ni} / \mathrm{Ir} / \mathrm{Au}$ diode increased from 1.01 to $1.10 \mathrm{eV}$. The values stated are from as deposited to $500{ }^{\circ} \mathrm{C}$ annealing. The improvement in the barrier heights could be due to better adhesion between the metalsemiconductor interface with increasing annealing temperature.

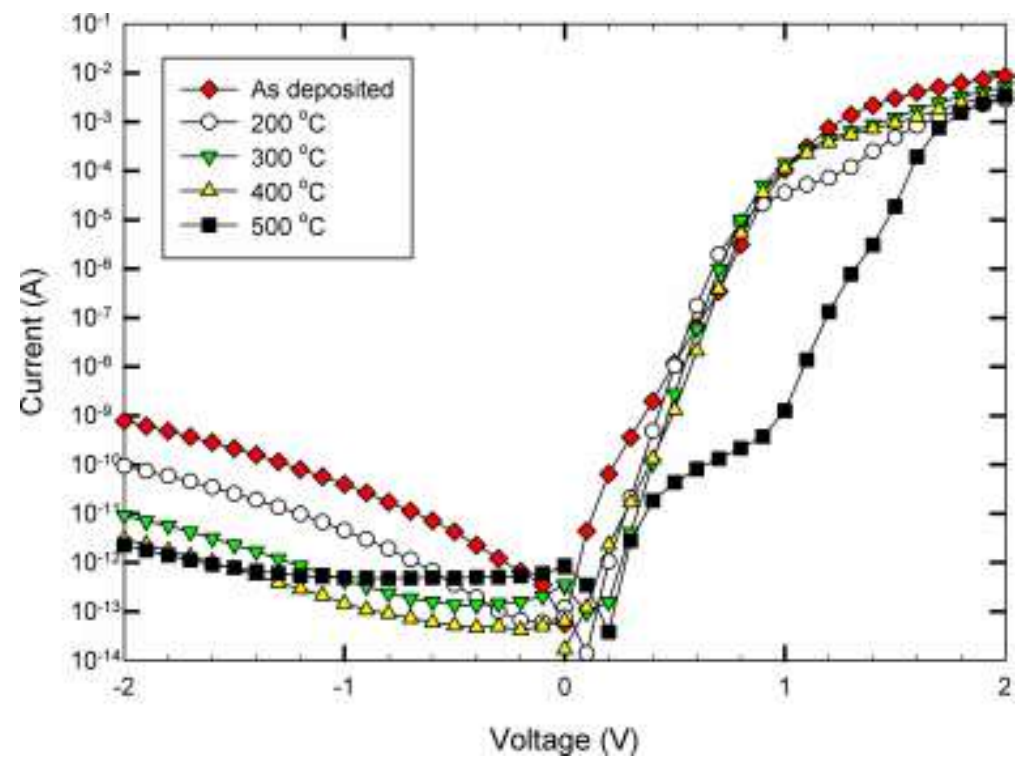

Fig. 1 I-V characteristics of Ni/Au Schottky photodiode measured at room temperature after annealing at different temperatures.

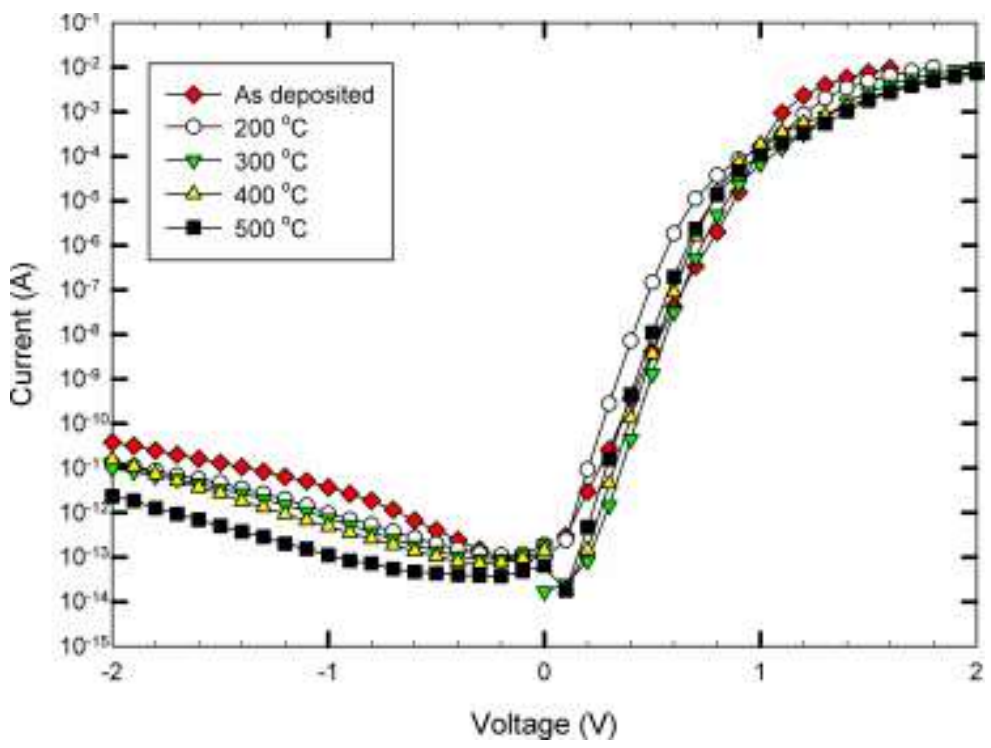

Fig. 2 I-V characteristics of Ni/Ir/Au Schottky photodiode measured at room temperature after annealing at different temperatures. 
The transmission of the Ni/Au and Ni/Ir/Au metal layers are shown in Fig. 3 and Fig. 4 respectively. The transmission of the $\mathrm{Ni} / \mathrm{Ir} / \mathrm{Au}$ metal layer was lower than that of the $\mathrm{Ni} / \mathrm{Au}$ layer, as was to be expected due to the additional Ir layer sandwiched between the $\mathrm{Ni}$ and $\mathrm{Au}$ layers. The transmission of light was dependent on the type of metal that the light was being radiated through and also on the wavelength of the radiation. The transmission through the $\mathrm{Ni} / \mathrm{Au}$ metal layer was relatively constant throughout the 200 to $360 \mathrm{~nm}$ range after annealing at lower temperatures. The trends of the transmission for the samples annealed at 400 and 500 ${ }^{\circ} \mathrm{C}$ are similar. Between 300 and $360 \mathrm{~nm}$, the layer showed a significant increase in transmission. In the wavelength range of 200 to $360 \mathrm{~nm}$, the transmission increased from 54 $\%$ as deposited to $85 \%$ after $500{ }^{\circ} \mathrm{C}$ annealing. The transmission of the $\mathrm{Ni} / \mathrm{Ir} / \mathrm{Au}$ metal layer varied more than that of the $\mathrm{Ni} / \mathrm{Au}$ metal layers. The as deposited, as well as the samples annealed at $200{ }^{\circ} \mathrm{C}$ and $300{ }^{\circ} \mathrm{C}$ had the same trend. The transmission decreased with increasing wavelength. For both layer systems, the $400{ }^{\circ} \mathrm{C}$ and $500{ }^{\circ} \mathrm{C}$ transmission spectra had a ' $u$-shaped' figure having their lowest transmission values at $290 \mathrm{~nm}$. At $400{ }^{\circ} \mathrm{C}$ annealing the transmission of the $\mathrm{Ni} / \mathrm{Ir} / \mathrm{Au}$ metal layer rose to its highest values throughout the 200 to $360 \mathrm{~nm}$ range. It can therefore be seen that the best temperature for annealing the $\mathrm{Ni} / \mathrm{Ir} / \mathrm{Au}$ metal layer was $400{ }^{\circ} \mathrm{C}$. Similarly, for the Ni/Au metal layer, the optimum annealing temperature was $500{ }^{\circ} \mathrm{C}$.

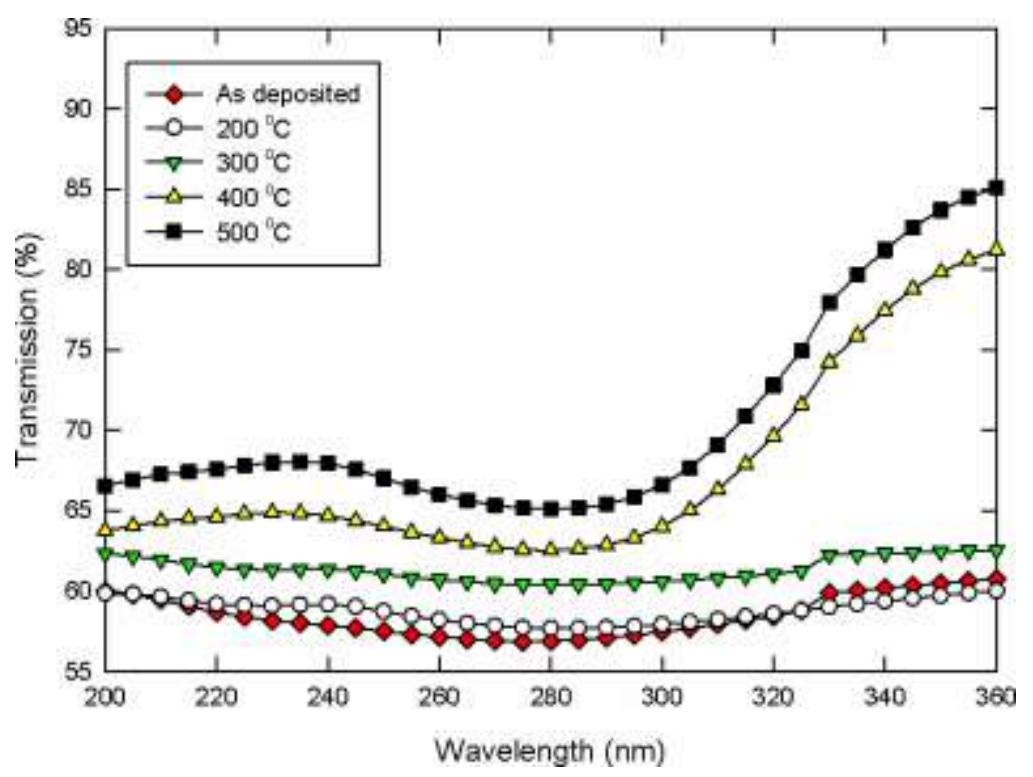

Fig. 3 Transmission vs. wavelength of a Ni/Au metal layer deposited on a quartz substrate measured at room temperature after annealing at different temperatures. 


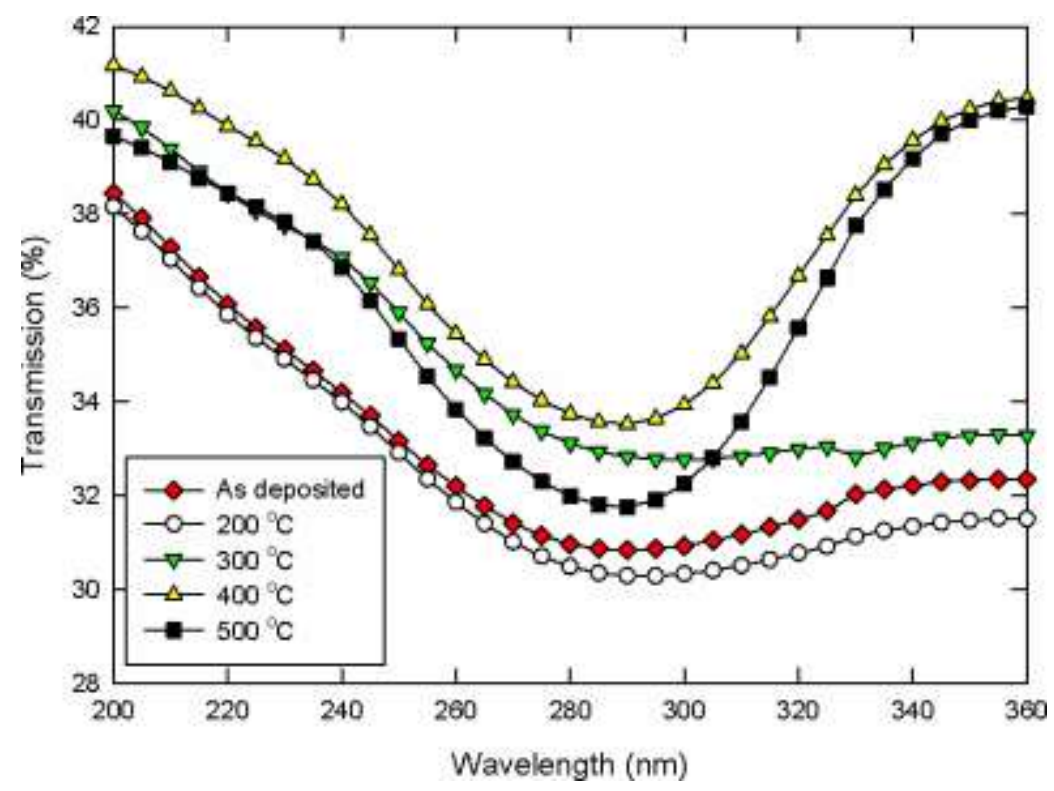

Fig. 4 Transmission vs. wavelength of a Ni/Ir/Au metal layer deposited on a quartz substrate measured at room temperature after annealing at different temperatures.

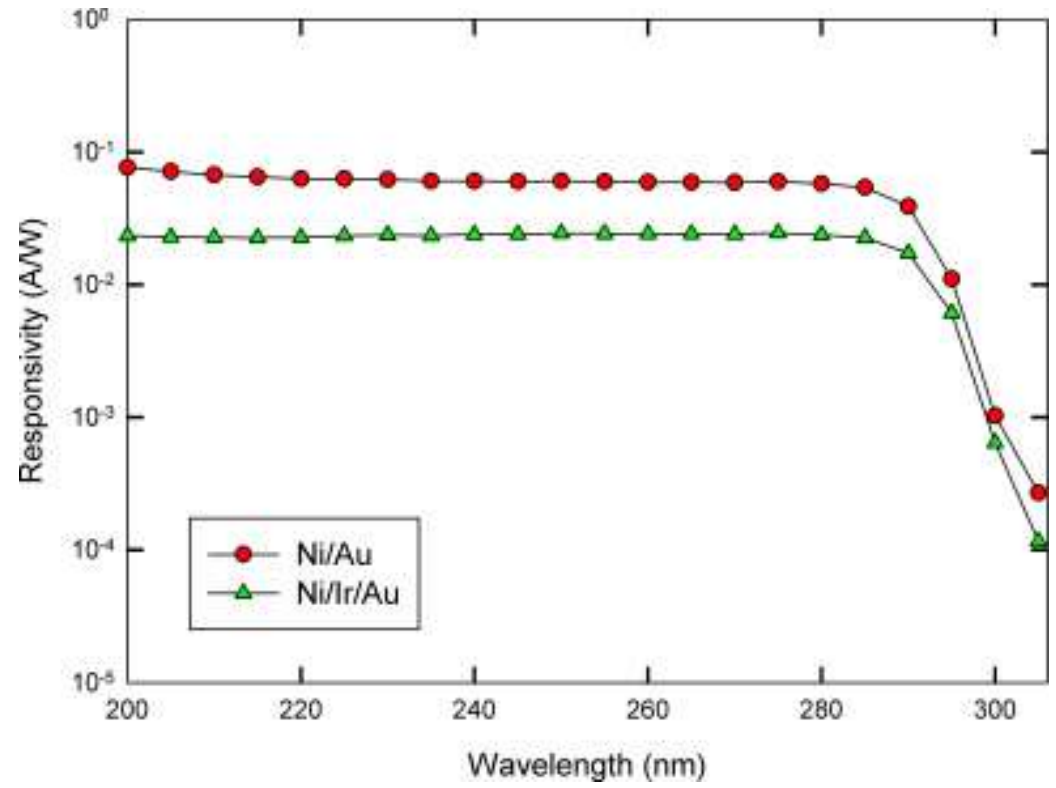

Fig. 5 The responsivity vs. the wavelength of a Ni/Au and Ni/Ir/Au Schottky photodiode.

Fig. 5 shows the responsivity of the $\mathrm{Ni} / \mathrm{Au}$ and $\mathrm{Ni} / \mathrm{Ir} / \mathrm{Au}$ Schottky photodiodes. The responsivity of the photodiodes was measured under a zero bias voltage. The UV to visible rejection ratio reached as high as $10^{2}$ for both photodiodes. The peak responsivity of the $\mathrm{Ni} / \mathrm{Au}$ photodiode was $0.077 \mathrm{~A} / \mathrm{W}$ at $200 \mathrm{~nm}$ and that of the $\mathrm{Ni} / \mathrm{Ir} / \mathrm{Au}$ photodiode was 0.025 
A/W at $275 \mathrm{~nm}$. The cut-off wavelength of the photodiodes was $292 \mathrm{~nm}$. The responsivity of the $\mathrm{Ni} / \mathrm{Au}$ photodiode was higher than that of the $\mathrm{Ni} / \mathrm{Ir} / \mathrm{Au}$ photodiode due to the fact that there was more radiation that reached the metal-semiconductor interface because the metal contact layer was thinner. When the radiation reached the metal-semiconductor interface, electron-hole pairs were generated which generated current in the photodiode.

\section{Conclusion}

The optical and electrical characteristics of $\mathrm{Ni} / \mathrm{Au}$ and $\mathrm{Ni} / \mathrm{Ir} / \mathrm{Au}$ Schottky photodiodes were investigated after annealing at different temperatures. The Ir inserted between the $\mathrm{Ni}$ and the Au seemed to have an effect on both the electrical and optical characteristics after annealing. The Schottky barrier height increased with annealing temperature to a maximum of $1.26 \mathrm{eV}$ for the $\mathrm{Ni} / \mathrm{Au}$ photodiode and $1.10 \mathrm{eV}$ for the $\mathrm{Ni} / \mathrm{Ir} / \mathrm{Au}$ photodiode after annealing at $500{ }^{\circ} \mathrm{C}$. The reverse current improved with annealing temperature up to $400{ }^{\circ} \mathrm{C}$ for the $\mathrm{Ni} / \mathrm{Au}$ Schottky photodiode and $500{ }^{\circ} \mathrm{C}$ for the $\mathrm{Ni} / \mathrm{Ir} / \mathrm{Au}$ photodiode. The peak responsivity of the $\mathrm{Ni} / \mathrm{Au}$ photodiode was $0.077 \mathrm{~A} / \mathrm{W}$ at $200 \mathrm{~nm}$ and that of the $\mathrm{Ni} / \mathrm{Ir} / \mathrm{Au}$ photodiode was 0.025 $\mathrm{A} / \mathrm{W}$ at $275 \mathrm{~nm}$. The cutoff wavelength obtained from the photodiodes was $292 \mathrm{~nm}$. The transmission of light through $\mathrm{Ni} / \mathrm{Au}$ and $\mathrm{Ni} / \mathrm{Ir} / \mathrm{Au}$ metal layers after different annealing temperatures was also investigated to observe the effect they have on the optical properties of the devices. The best annealing temperature for the $\mathrm{Ni} / \mathrm{Au}$ metal layer was $500{ }^{\circ} \mathrm{C}$ and that of the $\mathrm{Ni} / \mathrm{Ir} / \mathrm{Au}$ was $400{ }^{\circ} \mathrm{C}$.

\section{References}

[1] E. Muñoz, E. Monroy, J.L. Pau, F. Calle, F. Omnes, P. Gibart, J. Phys-Condens. Mat. 13 (2001) 7115.

[2] M.A. Khan, M. Shatalov, H.P. Maruska, H.M. Wang, E. Kuokstis, Jpn. J. Appl. Phys., 44 (10) (2005) 7191.

[3] F. Omnès, E. Monroy, E. Muñoz, J. Reverchon, Proc. of SPIE 6473 (2007) 64730E-1.

[4] M. Razeghi, A. Rogalski, J. Appl. Phys. 79 (10) (1996) 7433.

[5] H.C. Lee, Y.K. Su, J.C. Lin, Y.C. Cheng, T.C. Li, K.J. Chang, Solid-State Electron. 54 (2010) 488 .

[6] P.C. Chang, C.L. Yu, S.J. Chang, C.H. Liu, Thin Solid Films 516 (2008) 3324. 
[7] N. Miura, T. Nanjo, M. Suita, Y. Abe, T. Ozeki, H. Ishikawa, T. Egawa, IEEE T. Electron Dev. 51 (3) (2004) 297.

[8] N. Miura, T. Nanjo, M. Suita, T. Oishi, Y. Abe, T. Ozeki, H. Ishikawa, T. Egawa, T. Jimbo, Solid-State Electron. 48 (2004) 689.

[9] P.C. Chang, C.H. Chen, S.J. Chang, Y.K. Su, C.L. Yu, P.C. Chen, C.H. Wang, Semicond. Sci. Tech. 19 (2004) 1354.

[10] M. Diale, F.D. Auret, N.G. van der Berg, R.G. Odendaal, W.D. Roos, Appl. Surf. Sci., 246 (2005) 279.

[11] L.L. Smith, S.W. King, R.J. Nemanich, R.F. Davis, J. Electron. Mater. 25 (5) (1996) 805.

[12] S.M. Sze, Physics of Semiconductor Devices, John Wiley and Sons, New York, 1981.

[13] J.K. Sheu, Y.K. Su, G.C. Chi, W.C. Chen, C.Y. Chen, C.N. Huang, J.M. Hong, Y.C. Yu, C.W. Wang, E.K. Lin, J. Appl. Phys. 83 (6) (1998) 3172. 